\title{
Development of Intelligent Alumni Management System for Universities
}

\author{
Nayyar Ahmed Khan ${ }^{1 *}$, Ahmed Masih Uddin Siddiqi ${ }^{2} \&$ Mohammad Ahmad ${ }^{3}$ \\ ${ }^{I *}$ Lecturer, Computer Science, College of Computing and IT, Shaqra University, Saudi Arabia. \\ ${ }^{2}$ Lecturer, Computer Science, College of Applied Medicine, Shaqra University, Saudi Arabia. \\ ${ }^{3}$ Lecturer, Computer Science, College of Science and Humanities-Dawadami, Shaqra University, Saudi Arabia.
}

Copyright: @2021 Nayyar Ahmed Khan et al. This is an open access article distributed under the terms of the Creative Commons Attribution License, which permits unrestricted use, distribution, and reproduction in any medium, provided the original author and source are credited.

\section{ABSTRACT}

Alumni unit information management system allows communications between colleges and graduates. It represents way of how university can be in touch with its graduates. Further, it is a system to communicate a space for graduates where they could exchange thinking and opinions of any subject. Through their system, alumni can discover new employments opportunities they can apply for them. Alumni can also publish any announcement approved by system administrator. The system should collect information about working experience of graduates. It can improve communications and facilities teaching process. The current design focuses also on security, usability and accessibility.

Keywords: Alumni, Management, System.

\section{Introduction}

The need for communication between graduates and their colleges and universities increased in recent years to learn a lot about them and their needs and the labor market needs. This research continues to contribute to building a solid base among graduates and university students to learn more about the needs of the Saudi labor market of qualified labor enough to strengthen the labor market in the field of information technology and new efficiencies. Communication between graduates and university can be suitable for both sides the faculty also wants to keep in touch with its graduates using web application, providing a channel for professional and social communication between graduates themselves and the faculty [5]. The ALUMNI research focuses on design and implementation of the system that would accomplish these needs.

A Faculty of Engineering and Computer Sciences- Faculty of Engineering and Computer Sciences graduate is a person who has been studying at this faculty. During this period graduates establish a lot of social contacts with their classmates and their teachers as well. After graduating, these contacts are usually broken and only rarely continue. Generally, after a student leaves the university, he lost most of his contacts. However, the faculty does not want this trend to continue [1]. Faculty can see its graduates as potential business partners with possibility of cooperation after the studies. Graduates are very good source of information and critics that could help to improve the quality of the faculty. Nowadays a need for social networks sites among people especially those working in information technology field as graduates and all those involved in this vital area in this day and age. The main goal of this research is to develop new software which is able to support Alumni Unit to well manage and monitor alumni information. The system to develop in this research will able to support:

- The submitted solution will be a web-based application.

- The submitted solution will be available by the end of the second semester.

- Alumni information management, profiles, employment, surveys, and etc. 
- Alumni unit notes and their automatic posting or dispatching.

- Alumni employers management, surveys and new requirement announces.

- Alumni club management.

- Alumni unit event management.

There are the problems we should face in the construction of the proposed system to pursue graduate students including:

- Provide appropriate information to alumni so that he will be interested by alumni system.

- Allow alumni to create his profile and update its contents every time and everywhere.

- Make communication between system and user easy so that every alumnus can use the program.

- Allow private or government employers to seek alumni through their career improvement.

- Create forum discussion between all college alumni in organized way.

The main objective of this research - Alumni system- is to design and implement a system to follow the graduate students at the College of Computer Engineering and Sciences. Other sub-goals are:

- Allow alumni to be linked to alumni unit through the web.

- Allow alumni to participate in program curriculum evaluation and improvement.

- Allow alumni to publish their competences and skills using their profiles.

- Allow alumni to find a job using this system.

- Allow private employers (company and government administrations) to seek alumni and hire them if there is real need to be employed.

\section{Objectives of the Study}

It is very important for any system to be modelled very correctly and accurately before the development stage begins. In order to develop the system various concerns have to be taken care of [2]. This portion will include the system analysis results illustrated by UML Diagrams, class diagrams, activity diagrams, database diagram, entity relationship diagram, and flowcharts to elaborate the system in details.

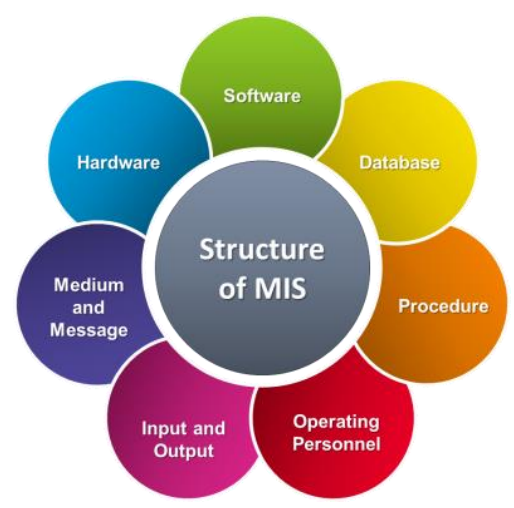

Fig.1. Components of the System 
At this stage, there are several activities carried out by research team and is:

- Identify users of the system

- Plan for the research

- Identify users of the system

There are three main users of our proposed system and employees who represent the university and administration of the proposed system Graduate students and singled those Companies and government agencies and private [3]. Goal of the analysis phase to determine what is expected from the proposed alumni in order to achieve the requirements of the user - Graduates and university staff and public and private institutions -

- User requirements can be divided into the following:

- Functional requirements: functions to be performed by the system for all user.

- Performance requirements: the speed of the system in tutors.

- Input requirements: a data.

- Output requirements: information.

- Quality requirements: reliability, security and ease of use and maintenance.

The design process translates requirements to represent the solution. Design focuses on the following:

- Architectural Design: integral system to parts of the software using the organization chart.

- Design data structures: A description of the data and files, as well as describe the relationships between files.

- Algorithm Design: is the process of writing the logical steps to parts of the software in the system.

- User interface design: design home screens for entry into the system.

Goal of the implementation phase:

Production of all programs using a programming language for system performs all the functions described have been prepared in the design phase [4].

The team performs the following tasks:

- Translating the design specifications for each part to program in a language compiler source.

- Translation program, research and correct the errors.

- Software test each part separately and then tested within the scope of the whole system and here you may discover errors in the design.

Goal of the testing phase:

Determine access to the desired results when the system is running. 
Test the new system must meet the following:

- Get rid of the linguistic and logical errors and executive.

- Determine user input errors.

- Assess the security of the system and speed performance.

- Discover any missing document and documenting the system.

- To test a new system usually use a sample of data and compare the output with the result obtained from the same sample manually.

- Must contain this sample on all possible cases to make sure there is no logical errors.

\section{Software Engineering of System}

The following section presents the complete set of functional and non-functional. Functional requirements are listed first,

- Graduate students.

- Supervisors of the employees of the university system.

- Companies or institutions that have the powers to communicate with graduate students.

System requirements

Alumni

- Allows alumni who have graduated college and have a number to complete their resumes through the system easily and conveniently.

- Update his/her information.

Company

- Gives the ability to give privileges to the companies and institutions are free.

- Search throughout system about specific CV.

University

- Allows the University to follow orders and their status.

- Counting system applications and the number and classified and watched.

Non-Functional Requirement:

- The System should be easy to use for all users performance.

- $\quad$ Easy to use GUI.

- The System should be Subject to maintenance if necessary. 
- The system shall be capable of restoring.

- The System should be flexibility.

- The System should be secure.

- The System should be Capacity.

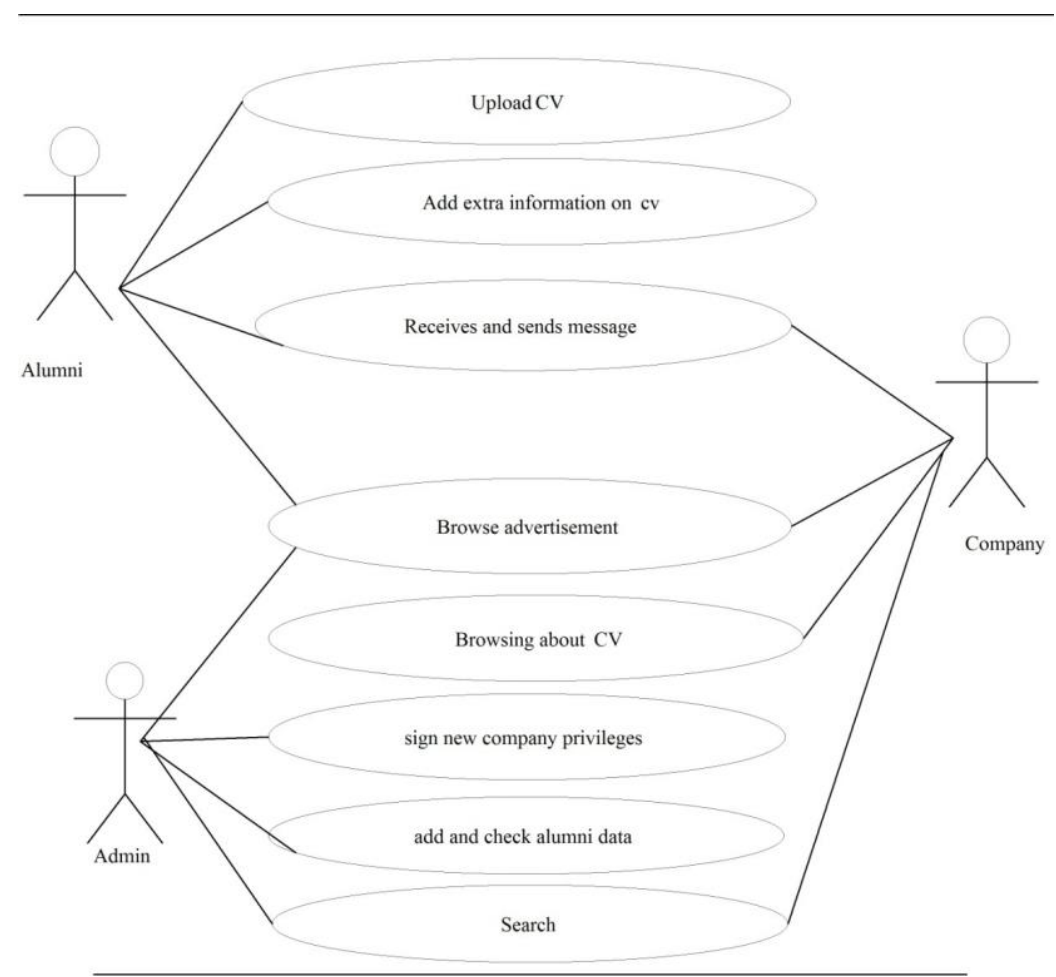

Fig.2. Use Case Analysis of the System

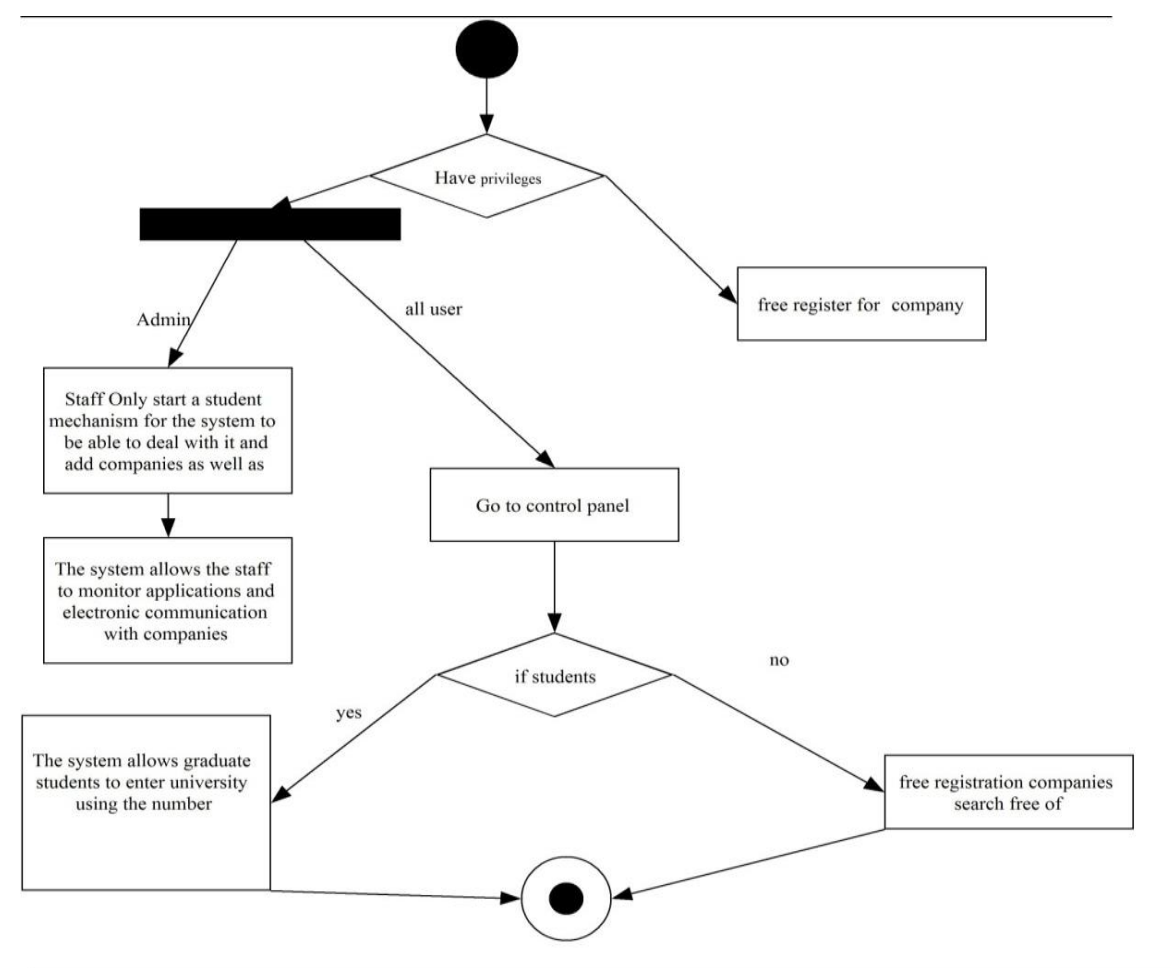

Fig.3. Activity Diagram of the System 


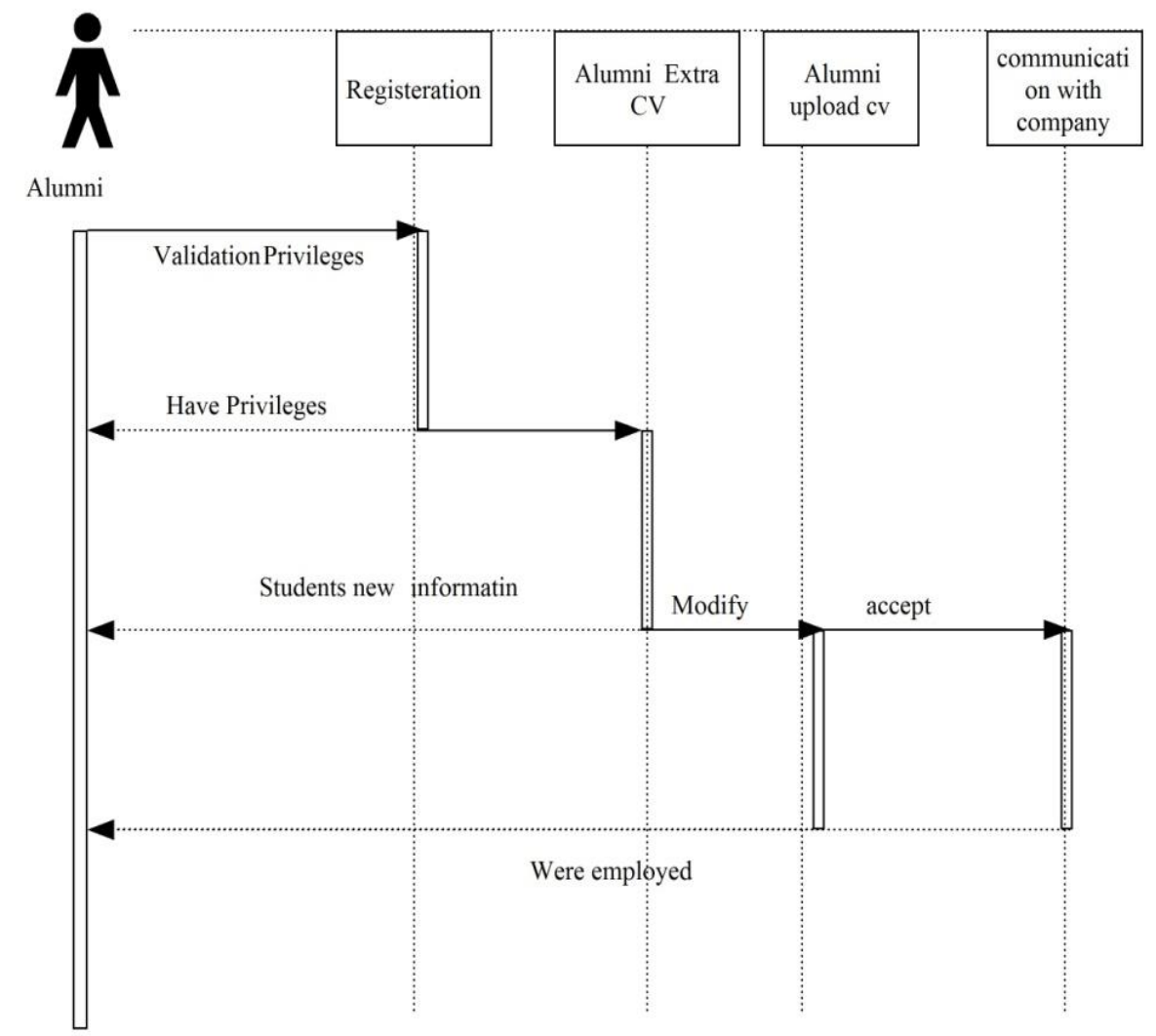

Fig.4a. Sequence-I Diagram of System

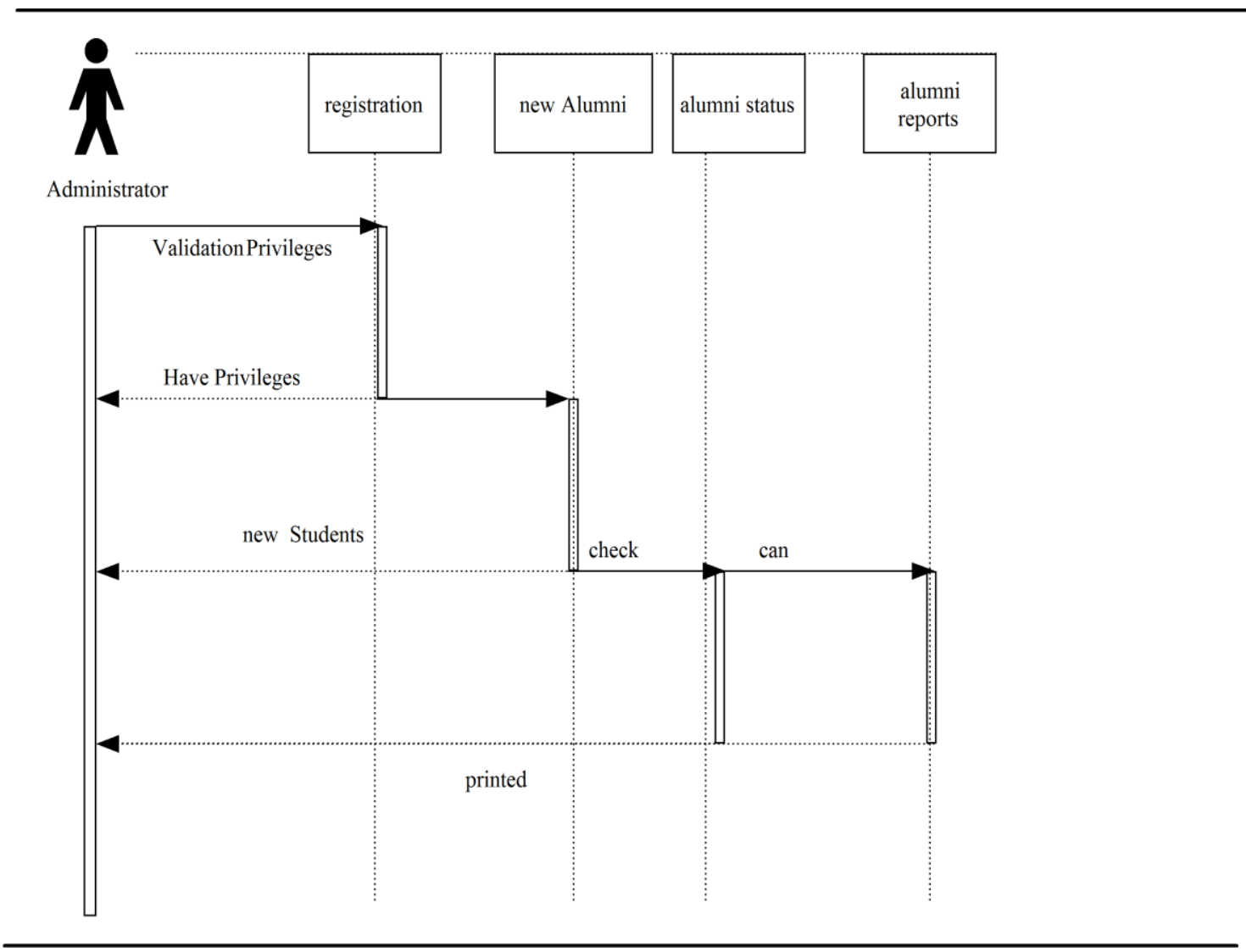

Fig.4b. Sequence -II Diagram of System 


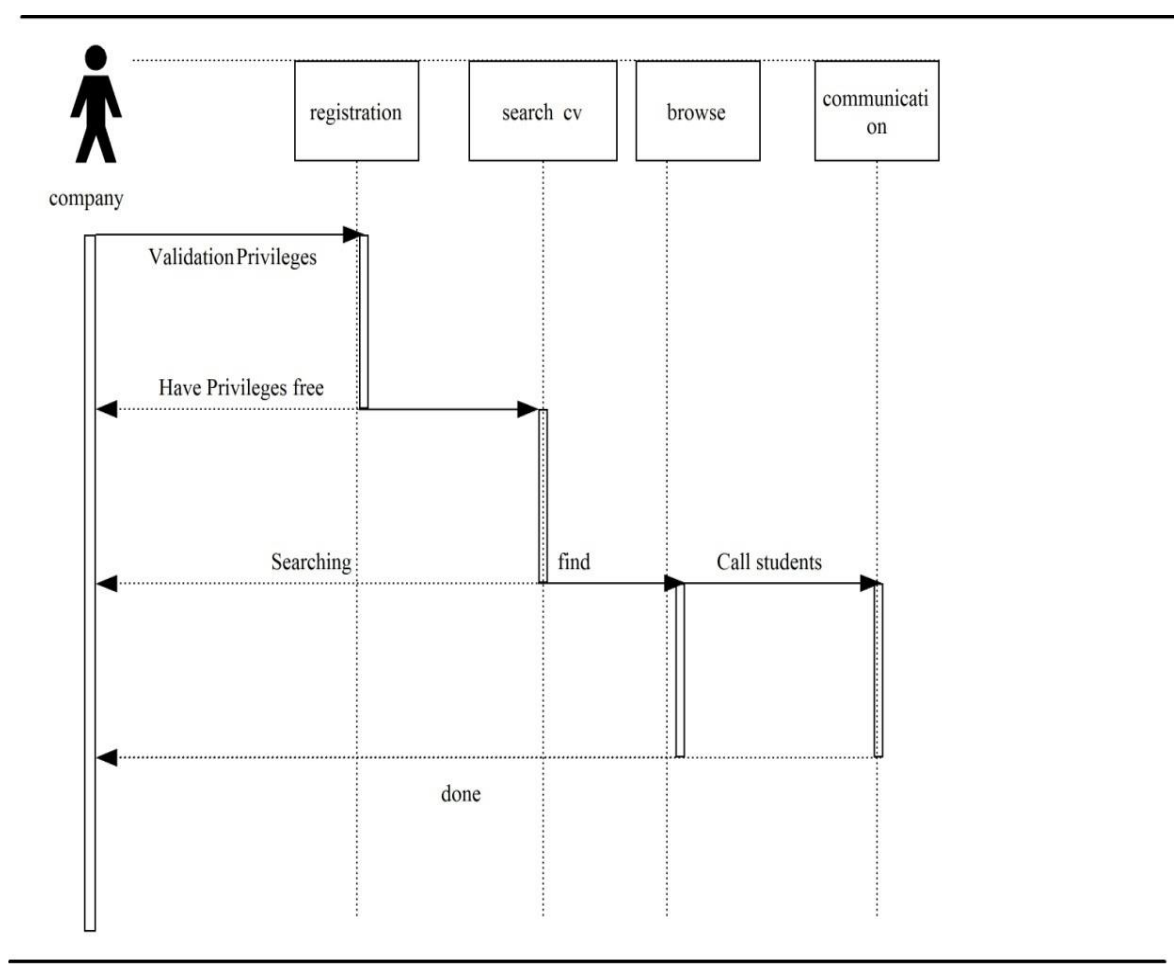

Fig.4c. Sequence -III Diagram of System

\section{Database Analysis of the System}

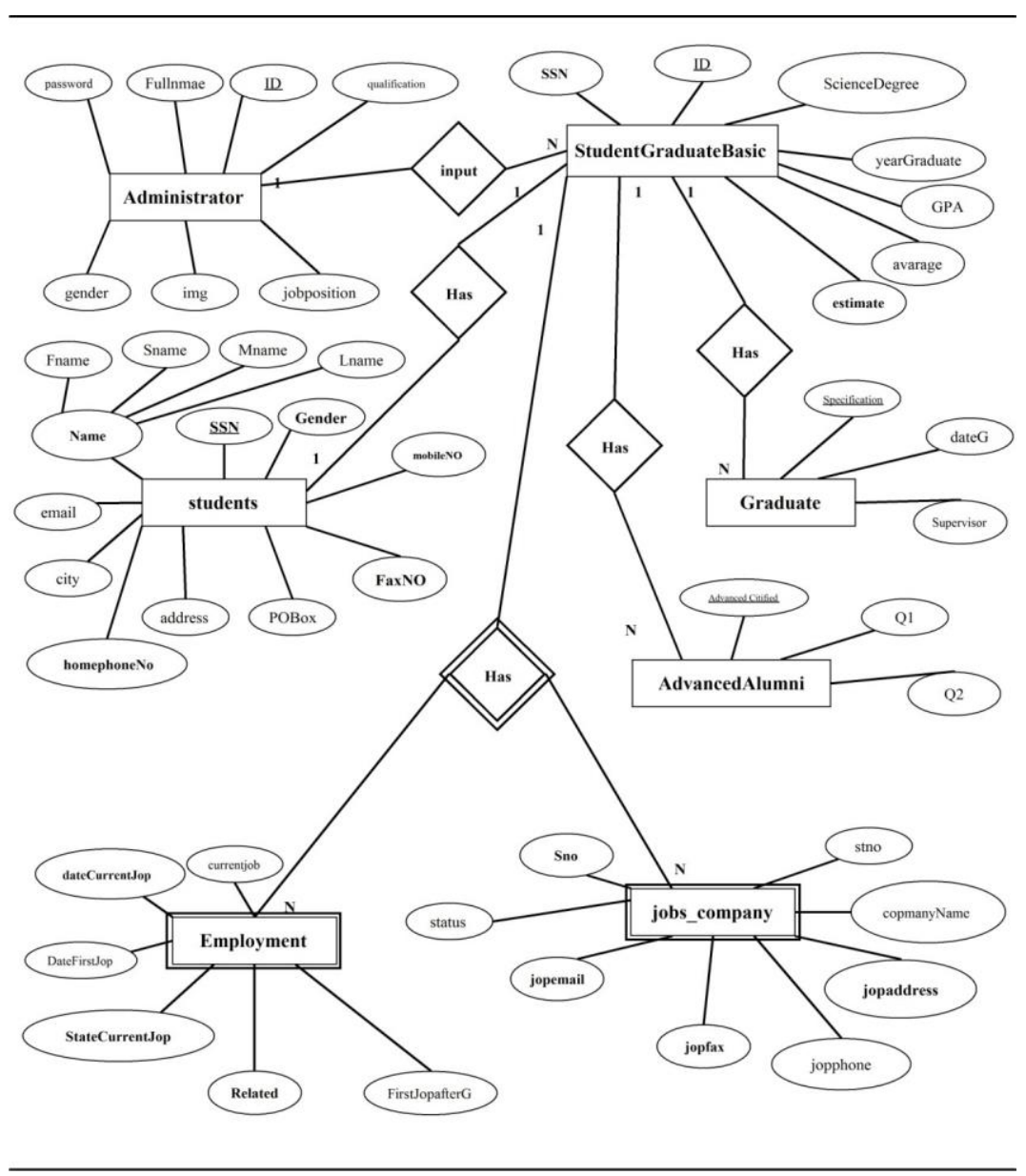

Fig.5. ER Diagram 
Class Diagram

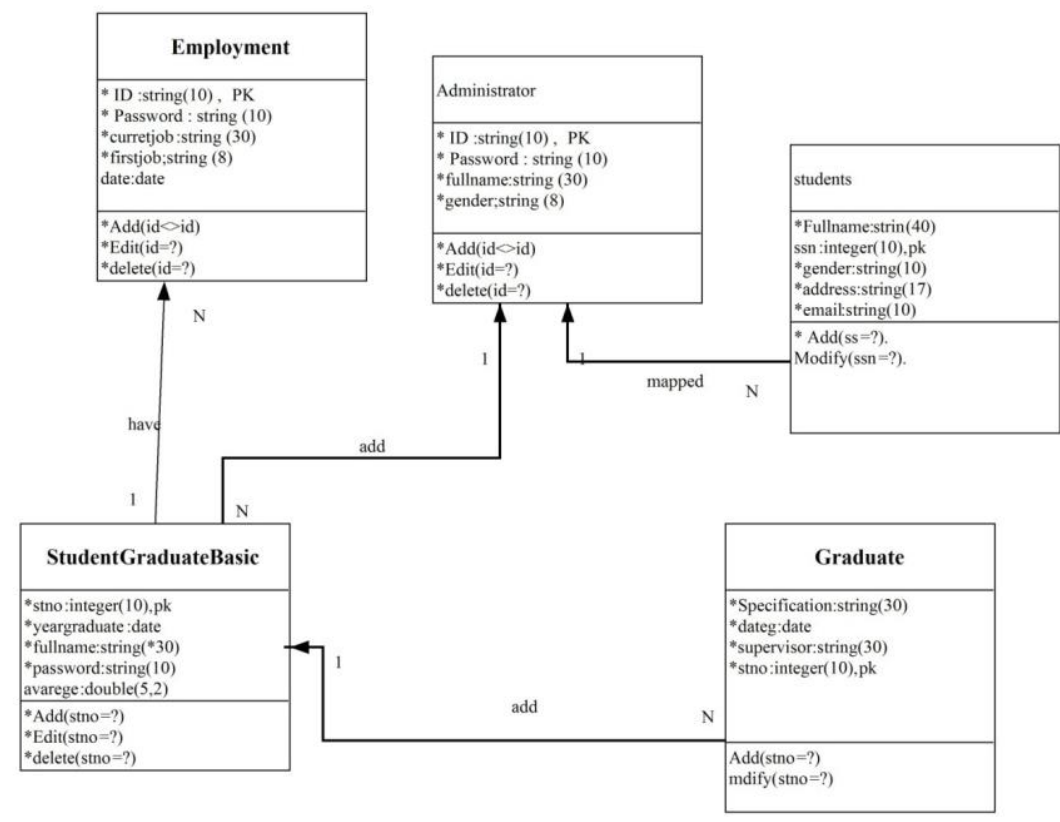

Fig.6. Database Schema Diagram

\section{Deployment of the System}

To work well, a computer/server that has the following requirements:

- I5 intel core or higher

- $\quad 1 \mathrm{~TB}$ of storage

- $16 \mathrm{~GB}$ of RAM

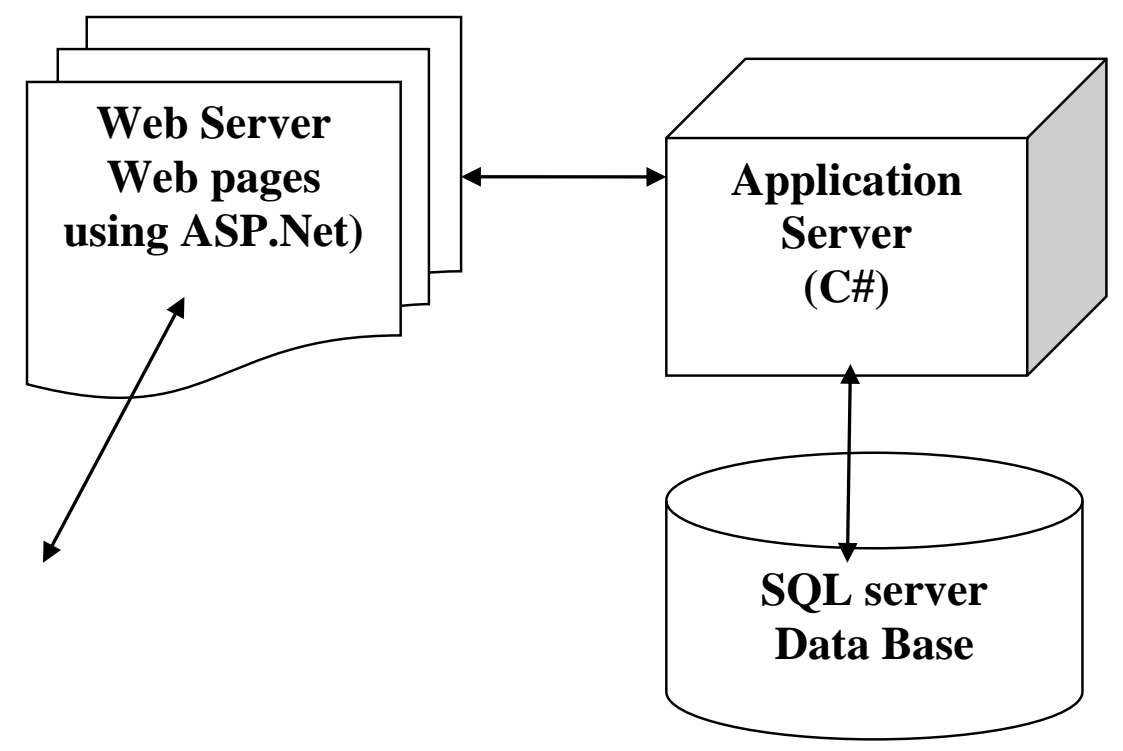

Fig.7. Architecture of Application Deployment 
Software that have been used when implementing this system.

\begin{tabular}{|c|c|c|}
\hline & Software Name & Description \\
\hline 1 & Microsoft windows pro 10 & The base operating system \\
\hline 2 & Microsoft Word 2013 & Used in creating all phases of the project documents. \\
\hline 3 & Draw.io & $\begin{array}{l}\text { Drawing application tool will be necessary to draw UML } \\
\text { diagrams. }\end{array}$ \\
\hline 4 & Adobe Photoshop CS6 & $\begin{array}{l}\text { This graph utility will be used to design backgrounds, Icons } \\
\text { and edit images. }\end{array}$ \\
\hline 5 & Visual studio 2015 & To design the pages and write codes. \\
\hline 6 & Android & Android Studio Program \\
\hline 7 & WS_FTP95 ver. 5.08 & To upload files to the web server \\
\hline 8 & Adobe acrobat reader & To read to documents that will be added to the website. \\
\hline 9 & MySQL & Database \\
\hline 10 & IIS Web server & Hosting the project files on Server \\
\hline
\end{tabular}

System includes the following:

- SQlserver 2008 program

- SQ Language

- C\#.Net Language

- Visual Stodio 2010 program

- $\quad$ ASP .Net 2010 .net 4.5

- Photoshop CC

- CSS + HTML5 code

\section{Conclusion}

The system designed is entitled to be used by the university domain for managing the information of the Alumni to be made available for the companies. This would empower the job prospects and job availability for the fresh graduate and the alumni students to the max. The system is really helpful for the working of the university and the graduates from the university. The administration will also be finding the system to be really helpful and easy to handle information of the alumni and manage the information without any issues and problems. The companies giving job to the graduates can verify authentic and secure data from the system directly without failure. 
Declarations

\section{Source of Funding}

This research did not receive any specific grant from funding agencies in the public, commercial, or not-for-profit sectors.

\section{Competing Interests Statement}

The authors declare no competing financial, professional and personal interests.

\section{Ethical Approval}

Ethical approval for this research was given based on institutional guidelines.

\section{Consent to participate}

The consent to participate in this research was sought for and approved by the subjects to be used.

\section{Consent for publication}

We declare that we consented for the publication of this research work.

\section{Availability of data and material}

Authors are willing to share data and material according to the relevant needs.

\section{References}

[1] Olorunfemi and Ashaolu, Olorunfemi A. I. and Ashaolu, M.O. A Pragmatic Approach in Engineering Education Teaching Methods and Industry Partnership, 2012, www.sefi.be/wp-content/abstracts/1261.pdf.

[2] P.H.Waghodekar, Industry-Institution Partnership: Impact on Globalisation, Journal of Engineering Education Transformations, 12(2): p.36-44, 1998.

[3] P.H.W. Aghodekar, D.B. Limaye, Institution's Role in Industry Institution Partnership, The Journal of Engineering Education, 9(4): p.47-55, 1996.

[4] K.B. Raina, B.S. Rathore, J.S. Saini, Linkage between Institute and Industry, Journal of Engineering Education Transformations, 6(2): p.1-7, 1992.

[5] Powers, D.R., Higher Education in Partnership with Industry, 1988. 